\section{The Role of ORAII in the} Odontogenic Differentiation of Human Dental Pulp Stem Cells
Journal of Dental Research 2015, Vol. 94(II) I560-1567

(C) International \& American Associations for Dental Research 2015

Reprints and permissions: sagepub.com/journalsPermissions.nav DOI: $10.1177 / 0022034515608128$ jdr.sagepub.com

\author{
S. Sohn ${ }^{1,2}$, Y. Park ${ }^{1,2}$, S. Srikanth ${ }^{3}$, A. Arai ${ }^{1,2}$, M. Song ${ }^{1,2}$, B. Yu', K.-H. Shin ${ }^{1,2,4}$,

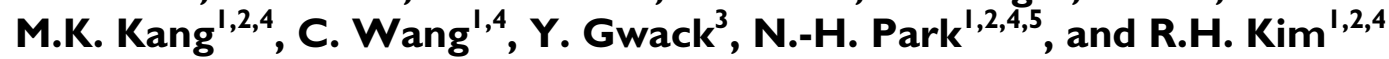

\begin{abstract}
Pulp capping, or placing dental materials directly onto the vital pulp tissues of affected teeth, is a dental procedure that aims to regenerate reparative dentin. Several pulp capping materials are clinically being used, and calcium ion $\left(\mathrm{Ca}^{2+}\right)$ released from these materials is known to mediate reparative dentin formation. ORAII is an essential pore subunit of store-operated $\mathrm{Ca}^{2+}$ entry (SOCE), which is a major $\mathrm{Ca}^{2+}$ influx pathway in most nonexcitable cells. Here, we evaluated the role of ORAII in mediating the odontogenic differentiation and mineralization of dental pulp stem cells (DPSCs). During the odontogenic differentiation of DPSCs, the expression of ORAII increased in a time-dependent manner. DPSCs knocked down with ORAII shRNA (DPSC/ORAIlsh) or overexpressed with dominant negative mutant ORAII ${ }^{\mathrm{E} 106 \mathrm{Q}}$ (DPSC/EI06Q) exhibited the inhibition of $\mathrm{Ca}^{2+}$ influx and suppression of odontogenic differentiation and mineralization as demonstrated by alkaline phosphatase (ALP) activity/staining as well as alizarin red $\mathrm{S}$ staining when compared with DPSCs of their respective control groups (DPSC/CTLsh and DPSC/CTL). The gene expression for odontogenic differentiation markers such as osteocalcin, bone sialoprotein, and dentin matrix protein I (DMPI) was also suppressed. When DPSC/CTL or DPSC/EI06Q cells were subcutaneously transplanted into nude mice, DPSC/CTL cells induced mineralized tissue formation with significant increases in ALP and DMPI staining in vivo, whereas DPSC/EI06Q cells did not. Collectively, our data showed that ORAII plays critical roles in the odontogenic differentiation and mineralization of DPSCs by regulating $\mathrm{Ca}^{2+}$ influx and that ORAII may be a therapeutic target to enhance reparative dentin formation.
\end{abstract}

Keywords: calcium, store-operated calcium entry (SOCE), reparative dentin formation, calcium release-activated calcium (CRAC) channels, pulp capping, odontogenic mineralization

\section{Introduction}

One of the major goals in restorative dentistry after deep caries removal is to enhance pulpal wound healing by regenerating reparative dentin, which will function as a physical barrier from dental materials to protect the underlying pulp tissues. Several dental materials including calcium hydroxide $\left(\mathrm{Ca}(\mathrm{OH})_{2}\right)$, mineral trioxide aggregate (MTA), and Biodentine (Septodont, Lancaster, PA, USA) are often used in clinics to induce reparative dentin formation by odontoblast-like dental pulp stem cells (DPSCs) (Hilton et al. 2013). Although these materials are different in nature and clinical outcomes, they all share some common properties that are believed to be important in forming reparative dentin such as a high $\mathrm{pH}$, antibacterial activities, their ability to solubilize bioactive materials from the dentin matrix, and calcium ion $\left(\mathrm{Ca}^{2+}\right)$ release (Bakland and Andreasen 2012). Among them, $\mathrm{Ca}^{2+}$ released from these materials has recently been shown to be one of the key factors mediating this healing process (Sangwan et al. 2013; Natale et al. 2015). However, the mechanism by which $\mathrm{Ca}^{2+}$ mediates odontogenic differentiation and mineralization is largely unknown.

$\mathrm{Ca}^{2+}$ plays indispensable roles in cell signaling pathways that are involved in maintaining and regulating normal biological processes (Apati et al. 2012; Tonelli et al. 2012). In most nonexcitable cells, $\mathrm{Ca}^{2+}$ influx is tightly regulated by the storeoperated $\mathrm{Ca}^{2+}$ entry (SOCE) pathway and is mediated through store-operated $\mathrm{Ca}^{2+}$ release-activated $\mathrm{Ca}^{2+}$ (CRAC) channels (Prakriya et al. 2006). Clinical studies showed that mutations in components of CRAC channels including ORAI1 and its associating protein, STIM1, are associated with clinical syndromes such as immunodeficiency, myopathy, and ectodermal dysplasia with defective dentition (McCarl et al. 2009; Picard et al. 2009), suggesting that $\mathrm{Ca}^{2+}$ regulation is also important in craniofacial regions including dentition.

\footnotetext{
'UCLA School of Dentistry, Los Angeles, CA, USA

${ }^{2}$ Laboratory of Viral Oncology and Aging Research, UCLA School of Dentistry, Los Angeles, CA, USA

${ }^{3}$ Department of Physiology, David Geffen School of Medicine at UCLA, Los Angeles, CA, USA

${ }^{4}$ UCLA Jonsson Comprehensive Cancer Center, Los Angeles, CA, USA

${ }^{5}$ David Geffen School of Medicine at UCLA, Los Angeles, CA, USA
}

A supplemental appendix to this article is published electronically only at http://jdr.sagepub.com/supplemental.

Corresponding Author:

R.H. Kim, UCLA School of Dentistry, Center for the Health Sciences, 10833 Le Conte Avenue, Room 43-09I, Los Angeles, CA 90095, USA.

Email: rkim@dentistry.ucla.edu 
ORAI1 is an essential pore subunit of SOCE, which is a major $\mathrm{Ca}^{2+}$ influx pathway in most nonexcitable cells (Feske et al. 2006). Upon stimulation, the cells release $\mathrm{Ca}^{2+}$ from the endoplasmic reticulum (ER), followed by extracellular $\mathrm{Ca}^{2+}$ influx through SOCE. This pathway not only refills the depleted ER $\mathrm{Ca}^{2+}$ stores but also provides a direct $\mathrm{Ca}^{2+}$ signal to activate downstream responses including the nuclear factor of activated T cells (NFAT) signaling pathway (Parekh and Putney 2005). ORAI1 has been extensively studied in immunology as NFAT is the transcription factor that is necessary for the activation, differentiation, and effector functions of $\mathrm{T}$ cells (Srikanth and Gwack 2013). Yet, the role of ORAI1 in functions of other cell types is not clear.

Recent studies showed the importance of ORAI1 in bone formation (Hwang et al. 2012; Robinson et al. 2012). Boneforming osteoblasts are similar to dentin-forming odontoblasts in that they both undergo secretion of the extracellular matrix and formation of mineralized hydroxyapatite (HA) (Gronthos et al. 2000; Gronthos et al. 2002). When the layer of odontoblasts at the dentin-pulpal interface becomes breached due to physical trauma such as direct pulp exposure, odontoblast-like pulp stem cells such as DPSCs are recruited and mediate pulpal wound healing by regenerating reparative dentin (Lin and Rosenberg 2011; Simon et al. 2011). However, the role of ORAI1 in the odontogenic differentiation of DPSCs is yet to be determined. Therefore, we hypothesized that ORAI1 might play critical roles in the odontogenic differentiation and mineralization of DPSCs by regulating $\mathrm{Ca}^{2+}$ influx.

\section{Materials and Methods}

\section{Cell Cultures}

Primary DPSCs were isolated from extracted human teeth as described previously (Gronthos et al. 2002; Mehrazarin et al. 2011; Kim et al. 2013; Williams et al. 2013). Extracted teeth were obtained according to the protocol approved by the institutional review board (protocol \#14-000270). From the primary cultures, multicolony-derived DPSCs were obtained and maintained in the basal medium containing $10 \%$ fetal bovine serum (FBS) in $\alpha$-MEM (Life Technologies, Grand Island, NY, USA). To induce these cells to undergo differentiation and mineralization, cells ( $<5$ passages) were cultured in the induction medium containing $10 \% \mathrm{FBS}, 100 \mu \mathrm{M}$ ascorbic acid 2-phosphate, $10 \mathrm{mM} \beta$-glycerophosphate, and $1.8 \mathrm{mM} \mathrm{KH}_{2} \mathrm{PO}_{4}$ (Sigma-Aldrich Inc., St. Louis, MO, USA) in $\alpha$-MEM (Life Technologies).

\section{Retroviral and Lentiviral Vector Construction and Transduction of Cells}

DPSCs were transduced with lentiviruses capable of knocking down ORAI1 or retroviruses capable of overexpressing ORAI1 ${ }^{\text {E106Q }}$, a dominant negative mutant that has a point mutation in the negatively charged residues (Prakriya et al. 2006; Gwack et al. 2007). The pLKO.1 and pLKO.1-ORAI1 sh lentiviral vectors (Sigma-Aldrich Inc.) and the pMSCV-CITE-eGFP-Puro
(MO70) and MO70-ORAI1 ${ }^{\text {E106Q }}$ retroviral vectors (Gwack et al. 2007) were used to prepare viruses as described previously (Kim et al. 2010). These vectors were transfected into GP2-293 universal packaging cells (Clonetech, Mountain View, CA, USA) along with the pVSV-G envelope plasmid using Lipofectamine 2000 (Life Technologies). Two days after transfection, the virus supernatant was collected and concentrated by ultracentrifugation. The virus pellet was suspended in serumfree $\alpha$-MEM (Life Technologies) and was used for immediate infections or stored at $-80^{\circ} \mathrm{C}$ for later use. DPSCs at passage 2 or 3 were infected with viruses containing pLKO.1, pLKO.1ORAI1sh, MO70, and MO70-ORAI1/E106Q in the presence of $6 \mu \mathrm{g} / \mathrm{mL}$ polybrene for $3 \mathrm{~h}$, and these cells were denoted as DPSC/CTLsh, DPSC/ORAI1sh, DPSC/CTL, and DPSC/ E106Q, respectively. All of these viruses consistently gave more than $90 \%$ of infection efficiency (Kim et al. 2010). The drug selection of cells began at $48 \mathrm{~h}$ after the infection with $1 \mu \mathrm{g} / \mathrm{mL}$ puromycin. The drug-resistant cells were maintained in subcultures as described above.

\section{Single-cell Intracellular Free $\mathrm{Ca}^{2+}$ Imaging}

Cells were plated on ultraviolet-sterilized coverslips $1 \mathrm{~d}$ prior to imaging. The next day, cells were loaded with $1 \mathrm{mM}$ Fura$2 \mathrm{AM}$ for $45 \mathrm{~min}$ at $25^{\circ} \mathrm{C}$. Intracellular $\left[\mathrm{Ca}^{2+}\right]_{i}$ measurements were performed using essentially the same methods as previously described (Kim et al. 2011). Briefly, cells were mounted in an RC-20 closed bath flow chamber (Warner Instrument Corp., Hamden, CT, USA) and analyzed on an Olympus IX51 epifluorescence microscope (Olympus, Center Valley, PA, USA) with SlideBook (Intelligent Imaging Innovations Inc., Denver, CO, USA) imaging software. Cells were perfused with $\mathrm{Ca}^{2+}$-free Ringer solution, and $\mathrm{Ca}^{2+}$ stores were passively depleted with $1 \mu \mathrm{M}$ thapsigargin. Fura- 2 emission was detected at $510 \mathrm{~nm}$ with excitation at 340 and $380 \mathrm{~nm}$, and the Fura-2 emission ratio (340/380) was acquired at every 5-s interval after subtraction of the background. For each experiment, 50 to 100 individual cells were analyzed using OriginPro (OriginLab Corp., Northampton, MA, USA) analysis software. Acquisition and image analysis including measurement of the Pearson correlation coefficient was performed using SlideBook (Intelligent Imaging Innovations Inc.) software, and graphs were plotted using OriginPro 8.5 (OriginLab Corp.).

\section{Quantitative Real-time Polymerase Chain Reaction ( $q R T-P C R)$}

Total RNA was isolated, and cDNA was created as described previously (Kim et al. 2013). qRT-PCR was performed in triplicate for each sample with LC480 SYBR Green I master mix (Roche, Indianapolis, IN, USA) using universal cycling conditions on LightCycler 480 (Roche). A total of 55 cycles were performed, and the second derivative $\mathrm{Cq}$ value determination method was used to compare fold differences. The primer sequences are available upon request. 


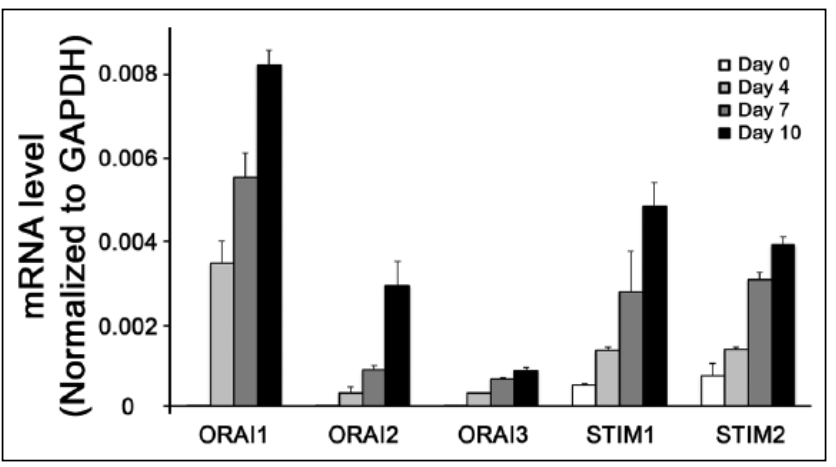

Figure I. Gene expression levels of ORAI and STIM. Dental pulp stem cells (DPSCs) were induced to undergo odontogenic differentiation. Cells were collected at $0,4,7$, and $10 \mathrm{~d}$, and quantitative real-time polymerase chain reaction was performed to examine the expression of ORAII, ORAI2, ORAI3, STIMI, and STIM2.

\section{Alkaline Phosphatase (ALP) Staining/Activity and Alizarin Red S (ARS) Staining}

ALP staining/activity was performed $7 \mathrm{~d}$ after induction using an ALP staining kit (86R-1KT; Sigma-Aldrich Inc.) according to the manufacturer's protocol. ARS staining was performed $3 \mathrm{wk}$ after odontogenic induction. For ARS staining, cells were fixed with $1 \%$ formalin/phosphate buffered saline (PBS) for 10 min and stained with $2 \%$ ARS solution ( $\mathrm{pH}$ of $4.1-4.3$ with $10 \%$ ammonium hydroxide) for $30 \mathrm{~min}$ at room temperature. The ARS solution was removed, and cells were washed with $\mathrm{ddH}_{2} \mathrm{O}$. The plates were photographed using both a microscope and camera. For the quantification of ARS staining, stained cells were destained in 10\% acetylpyridinium chloride (SigmaAldrich Inc.) and measured at $562 \mathrm{~nm}$ using a microplate reader.

\section{Subcutaneous Transplantation in Nude Mice}

Subcutaneous transplantation of the cell mixture was performed using nude mice as previously described (Fan et al. 2009) according to guidelines approved by the Chancellor's Animal Research Committee (ARC\# 2004-031). Briefly, approximately $2.0 \times 10^{6}$ of DPSC/CTL or DPSC/E106Q cells in $40 \mu \mathrm{L}$ of medium were mixed with $40 \mathrm{mg}$ of $\mathrm{HA} /$ tricalcium phosphate (TCP) ceramic particles (Zimmer, Carlsbad, CA, USA). The mixture was incubated at $37{ }^{\circ} \mathrm{C}$ for $2 \mathrm{~h}$ with gentle shaking and then transplanted subcutaneously into the dorsal suprascapular regions of 10-wk-old immunocompromised nude mice that were randomly assigned (nu/nu; $n=4$ per group) (Charles River Laboratories, Wilmington, MA, USA). The mice were housed in the pathogen-free UCLA vivarium under daily monitoring by veterinarians. Eight weeks after transplantation, the transplants were harvested. Half of the tissues were used to prepare cryosections, and the other half were used to prepare formalin-fixed paraffin-embedded (FFPE) sections. This animal study is in compliance with the ARRIVE guidelines.

\section{Mineralized Tissue Quantification and Immunohistochemical Staining}

Half of the tissues were fixed with $4 \%$ paraformaldehyde in PBS (pH 7.4) at $4{ }^{\circ} \mathrm{C}$ overnight and stored in 70\% ethanol solution. These tissues were decalcified with 5\% EDTA and 4\% sucrose in PBS (pH 7.4). Decalcification continued for $2 \mathrm{wk}$ at $4{ }^{\circ} \mathrm{C}$, and the decalcification solution was changed daily. Tissue samples were sent to the UCLA Translational Pathology Core Laboratory and processed for FFPE sections. Sectioned slides were stained using hematoxylin and eosin. Four images were taken from each section under a microscope $(\times 40)$ (Model DP72; Olympus), and quantitative analysis of mineralized tissues was performed using ImageJ (National Institutes of Health, Bethesda, MD, USA). Immunohistochemistry staining was performed with anti-DMP1 (MABD19; Millipore, Billerica, MA, USA) on 4- $\mu$ m-thick sections according to the manufacturer's protocol. The samples were counterstained with hematoxylin, and photographs were taken under a microscope.

\section{Cryostat Sectioning and ALP Staining}

The other half of the tissues was snap-frozen in hexane using liquid nitrogen and 2-methylbutane and embedded in a 5\% carboxymethyl cellulose gel. Five-micrometer-thick sections were prepared using the Kawamoto film method (Cryofilm transfer kit; Finetec, Tokyo, Japan). The sections were fixed in ice-cold 5\% acetic acid in ethanol and subjected to ALP staining using an ALP staining kit (86R-1KT; Sigma-Aldrich Inc.) according to the manufacturer's protocol.

\section{Statistical Analysis}

The outcome measurements from the experiments were displayed as the mean \pm standard deviation. To compare the means of outcome measurements, the Student's $t$ test was conducted with a significance level of 0.05 using SPSS v18.0 software (IBM Corp., Armonk, NY, USA).

\section{Results}

\section{Expression of ORAI and STIM during Odontogenic Differentiation}

To examine whether CRAC channels are involved in odontogenic differentiation, we screened for the gene expression of ORAI1, ORAI2, and ORAI3, as well as STIM1 and STIM2, during odontogenesis in DPSCs. We found that all of these genes were strongly induced in a time-dependent manner as DPSCs undergo odontogenic differentiation (Fig. 1A-E). In particular, ORAI1 expression was more significantly induced, suggesting that among different ORAI1 family members, ORAI1 may play an important role during the odontogenic differentiation of DPSCs. 


\section{Knockdown of ORAII Expression in DPSCs Inhibits Odontogenic Differentiation and Mineralization In Vitro}

DPSCs infected with retroviruses expressing ORAI1 shRNA were able to knock down endogenous ORAII up to $70 \%$ (Fig. 2A). SOCE is impaired in DPSC/ORAI1sh cells, indicating that ORAI1 knockdown functionally inhibited $\mathrm{Ca}^{2+}$ influx (Fig. 2B). When DPSC/CTLsh cells were grown in the odontogenic medium, these cells underwent odontogenic differentiation and mineralization as demonstrated by increased ALP staining/ activity and ARS staining; however, DPSC/ORAI1sh cells exhibited diminished ALP staining/activity and ARS staining (Fig. 2C, D). Similarly, qRT-PCR revealed the suppressed expression of odontogenic markers including osteocalcin $(O C)$, bone sialoprotein $(B S P)$, and dentin matrix protein 1 (DMP1) (Fig. 2G-J). Collectively, these data indicate that ORAI1 is essential in odontogenic differentiation and mineralization.

\section{Dominant Negative Mutant ORAII EI06Q Inhibits Odontogenic Differentiation and Mineralization In Vitro}

To examine whether the function of ORAI1 is directly associated with impaired odontogenic differentiation, we overexpressed the dominant negative mutant, ORAI1 ${ }^{\text {E106Q }}$, in DPSCs (Fig. 3A). Compared with DPSC/CTL cells, DPSC/E106Q cells showed impaired store-operated $\mathrm{Ca}^{2+}$ influx (Fig. 3B) and suppressed ALP staining (Fig. 3C). ALP expression was significantly suppressed when DPSC/E106Q cells were induced to undergo odontogenic differentiation (Fig. 3D). The timedependent suppression of odontogenic markers such as $O C$, $B S P$, and $D M P 1$ was also observed (Fig. 3E-H), indicating that abrogation of the ORAI1 function also inhibits odontogenic differentiation.

\section{Dominant Negative Mutant ORAII EI06Q Inhibits Odontogenic Differentiation and Mineralization In Vivo}

To examine whether ORAI1 plays an important role in odontogenic differentiation and mineralization in vivo, we transplanted DPSC/CTL or DPSC/E106Q cells in nude mice subcutaneously. After $8 \mathrm{wk}$, all mice survived without any notable health conditions, and the harvested tissues did not show any gross differences in size (data not shown). Histological examination revealed significant formation of mineralized tissues in the mass of DPSC/CTL cells, whereas no mineralized tissues were formed in the mass of DPSC/ E016Q cells (Fig. 4A, B). ALP staining on cryosections revealed significant amounts of ALP enzymatic activity in DPSC/CTL cells compared to none in DPSC/E106Q cells (Fig. 4C). Furthermore, consistent with the in vitro qRT-PCR results, immunohistochemistry staining for DMP1 showed notable staining patterns in the mass of DPSC/CTL cells, whereas no staining was shown in the mass of DPSC/E016Q cells nor from controlled isotypes (Fig. 4D and Appendix Fig.). These data indicate that abrogating functions of ORAI1 also suppressed odontogenic differentiation and mineralization in vivo.

\section{Discussion}

ORAI1 is a CRAC channel that plays an important role in regulating $\mathrm{Ca}^{2+}$ influx in most nonexcitable cells (Prakriya et al. 2006). Here, we found that ORAI1 is required for the odontogenic differentiation and mineralization of DPSCs both in vitro and in vivo. To the best of our knowledge, this is the first study reporting an essential role of ORAI1 in the odontogenic differentiation and mineralization of DPSCs.

Recent studies showed that ORAI1 plays an important role in mediating osteogenic differentiation and mineralization in osteoblasts. Orail ${ }^{-/-}$mice exhibited osteoporosis phenotypes, and bone marrow-derived stromal cells (BMSCs) from Orail $^{-/}$ mice showed diminished ALP and ARS staining in vitro (Hwang et al. 2012). Interestingly, Robinson et al. (2012) observed that these Orail $^{-/-}$mice exhibited smaller teeth with thin enamel. In line with these findings, our study showed that ORAI1 plays an important role in the differentiation and mineralization of DPSCs. We demonstrated this by nullifying $\mathrm{Ca}^{2+}$ influx through knocking down ORAI1 expression or by overexpressing the dominant negative form of ORAI ${ }^{\mathrm{E} 106 \mathrm{Q}}$ in vitro (Figs. 2 and 3). We further showed that DPSCs expressing ORAI1 ${ }^{\text {E106Q }}$ exhibited the suppressed formation of mineralized tissues in vivo (Fig. 4). Our study, along with others using BMSCs, demonstrated the indispensable functions of ORAI1 not only in bone but also in tooth homeostasis.

Historically, $\mathrm{Ca}(\mathrm{OH})_{2}$ has been used as a direct pulp capping material for many years, and it is generally believed that high $\mathrm{pH}$ due to the $\mathrm{OH}^{-}$group is largely responsible for reparative dentin formation in vivo by creating an alkaline environment that promotes the mineralization process (Kohn et al. 2002; Ferracane et al. 2010; Luca et al. 2010). However, increasing lines of evidence support a notion that $\mathrm{Ca}^{2+}$ released from these direct pulp capping materials may actively participate in reparative dentin formation (Sangwan et al. 2013; Natale et al. 2015). Indeed, a recent study comparing $\mathrm{Ca}(\mathrm{OH})$ and MTA demonstrated that, although both materials release $\mathrm{Ca}^{2+}$ over $28 \mathrm{~d}, \mathrm{Ca}^{2+}$ released from Dycal containing $\mathrm{Ca}(\mathrm{OH})_{2}$ was significantly lower than MTA (Natale et al. 2015). Biodentine (Septodont), another form of direct pulp capping material composed of tricalcium silicate that induces reparative dentin formation, also has been shown to release significant amounts of $\mathrm{Ca}^{2+}$ (Nowicka et al. 2013; Camilleri 2014).

It is noteworthy that calcium phosphate ceramics such as HA and $\beta$-TCP are commonly used as bone grafting materials. A previous study showed that, between 2 materials, $\beta$-TCP is more potent in inducing bone formation (Yuan et al. 2010), and such a difference was shown to be associated with more $\mathrm{Ca}^{2+}$ release in $\beta$-TCP when compared with HA (Barradas et al. 2013). The free form of $\mathrm{Ca}^{2+}$ is known to induce mineralization (Nakamura et al. 2010; Cheng et al. 2013), and osteoblasts are 


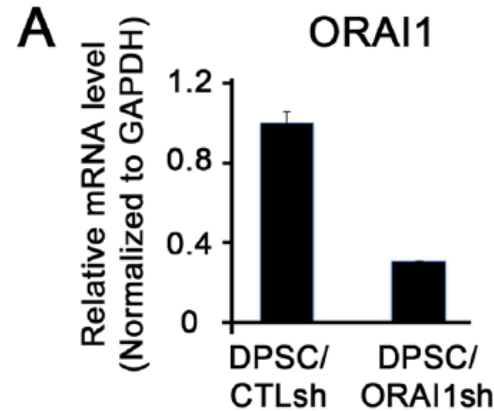

C
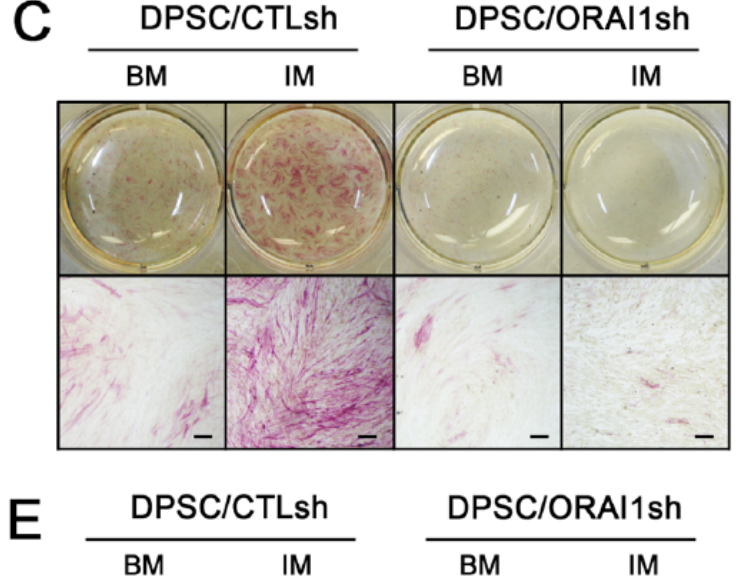

DPSC/ORAl1sh

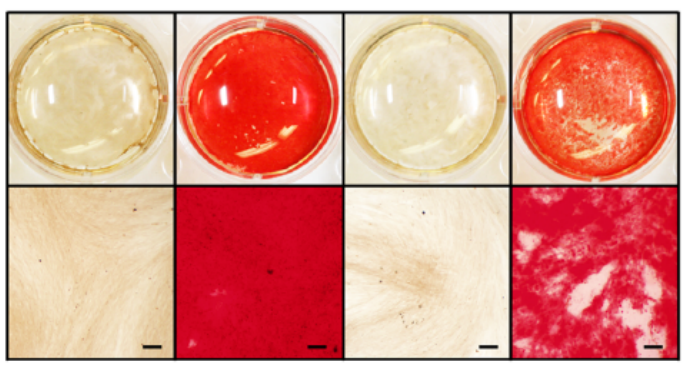

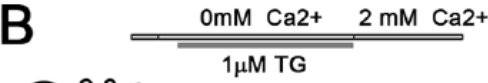

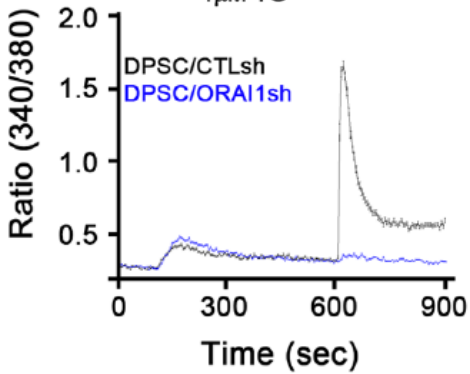

D

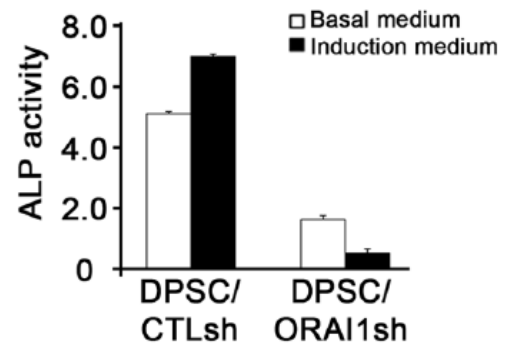

F

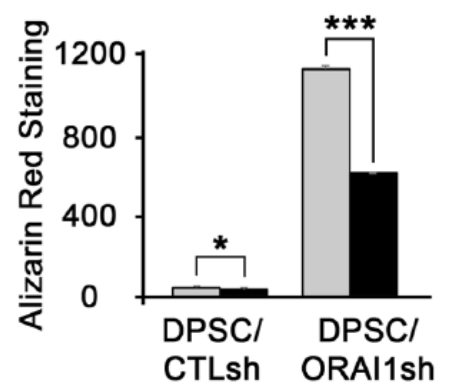

G

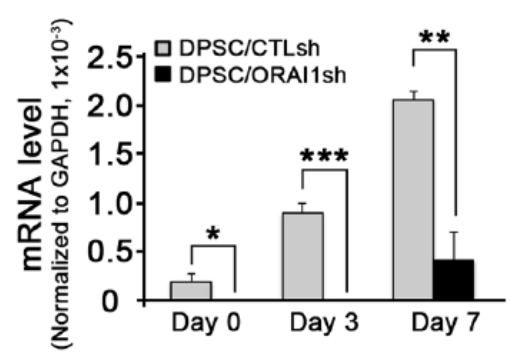

$\mathrm{H}$

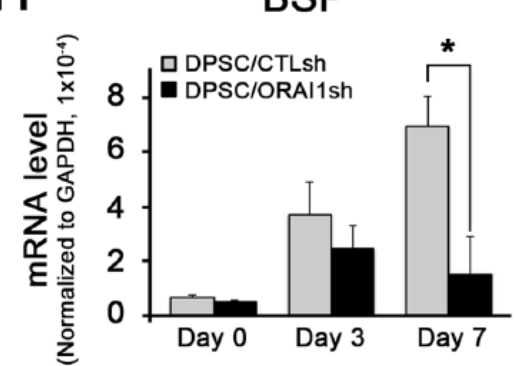

DMP1

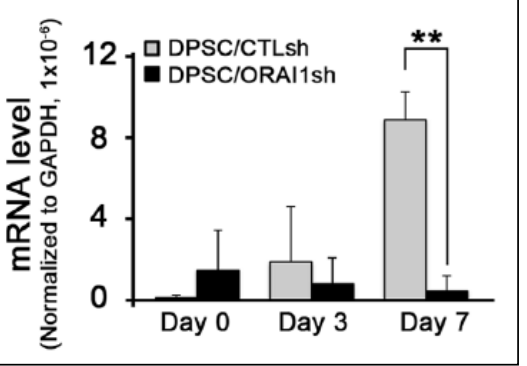

Figure 2. Knockdown of ORAII in dental pulp stem cells (DPSCs) inhibits odontogenic differentiation and mineralization in vitro. (A) DPSCs were infected with lentiviruses containing ORAII shRNA. (B) Intracellular $\mathrm{Ca}^{2+}$ imaging assay was performed to confirm ORAII function. TG, thapsigargin. (C, D) DPSC/CTLsh and DPSC/ORAII sh cells underwent odontogenic differentiation for $7 \mathrm{~d}$. Alkaline phosphatase (ALP) staining was performed, and ALP activity was measured. (E) Alizarin red S (ARS) staining was performed 3 wk after odontogenic differentiation. (F) ARS staining was quantified. (G-I) Cells were harvested at 0,3 , and $7 \mathrm{~d}$, and quantitative real-time polymerase chain reaction was performed for osteocalcin $(O C)$, bone sialoprotein $(B S P)$, and dentin matrix protein I $(D M P I)$. $* P<0.05$, $* * P<0.05$, and $* * * P<0.005$.

known to propagate the $\mathrm{Ca}^{2+}$ signaling pathway (Jørgensen et al. 2000). In human pulp cells, increased extracellular $\mathrm{Ca}^{2+}$ was shown to alter the expression of bone-related genes including BMP-2 (Rashid et al. 2003; Tada et al. 2010). Therefore, it is tempting to speculate that, among all the other known odontogenic factors (e.g., high $\mathrm{pH}$ ) in direct pulp 


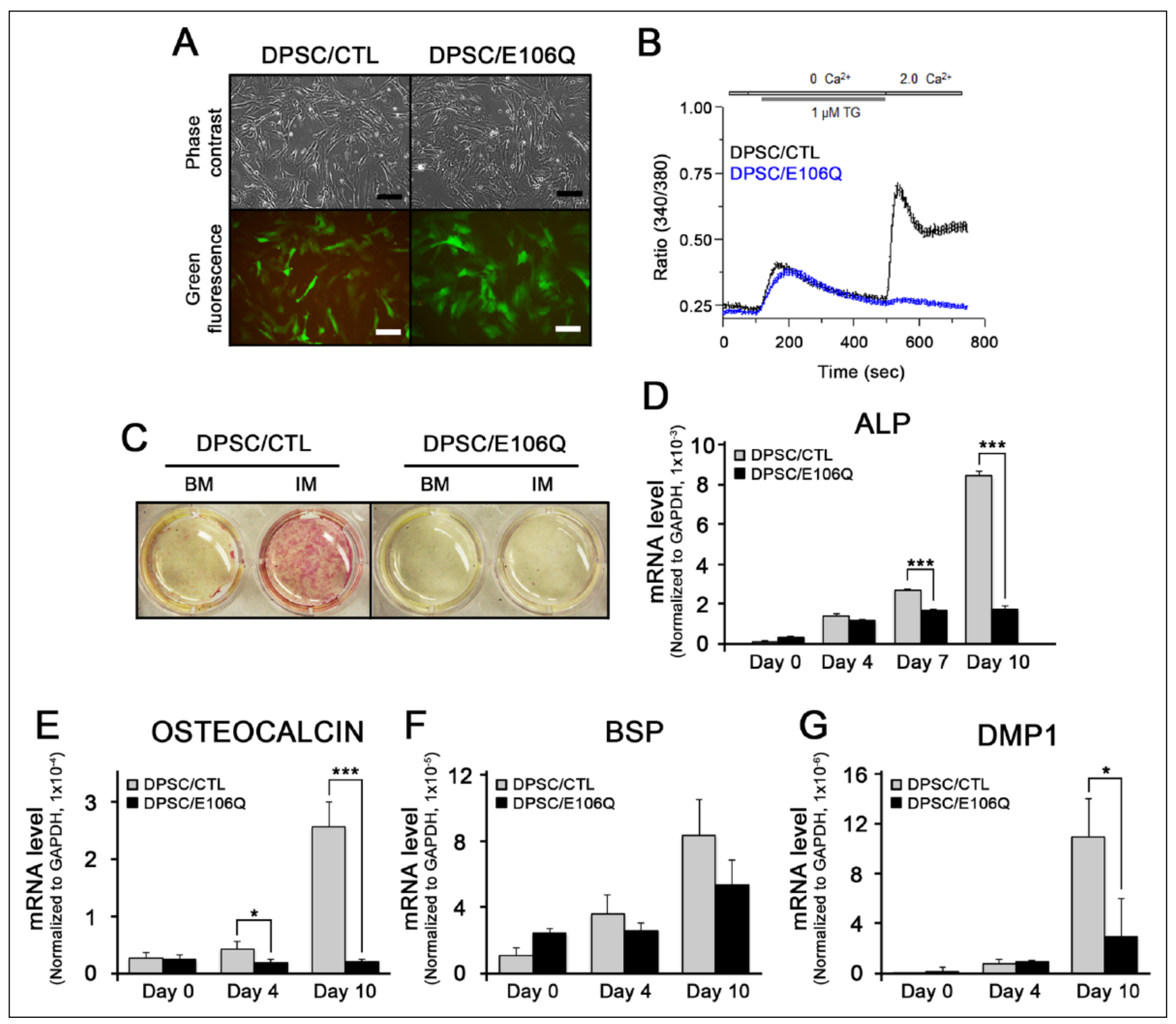

Figure 3. The dominant negative mutant ORAII ${ }^{\mathrm{E} 106 \mathrm{Q}}$ inhibits the odontogenic differentiation and mineralization of dental pulp stem cells (DPSCs) in vitro. (A) DPSCs were infected with retroviruses containing ORAII ${ }^{\mathrm{El} 06 \mathrm{Q}}$, and expression was confirmed using green fluorescence. (B) Intracellular $\mathrm{Ca}^{2+}$ imaging assay was performed to further confirm the ORAII function. TG, thapsigargin. (C) DPSC/CTL and DPSC/EI06Q cells underwent odontogenic differentiation for $7 \mathrm{~d}$. Alkaline phosphatase (ALP) staining was performed. (D-G) Cells were harvested at 0, 4, 7, and I0 d, and quantitative real-time polymerase chain reaction was performed for $A L P$, osteocalcin $(O C)$, bone sialoprotein $(B S P)$, and dentin matrix protein I $(D M P I)$. *P $<0.05$, **P $<0.05$, and $* * * P<0.005$.

capping materials, $\mathrm{Ca}^{2+}$ released from $\mathrm{Ca}(\mathrm{OH})_{2}$, MTA, or Biodentine (Septodont) may be the main component in inducing reparative dentin formation.

Our study demonstrated that ORAI1 plays a key role in odontogenic differentiation by mediating $\mathrm{Ca}^{2+}$ influx. $\mathrm{Ca}^{2+}$ channels other than ORAI1 such as the L-type voltage-gated $\mathrm{Ca}^{2+}$ channel (L-VGCC) are known to be involved in the mineralization process (Barradas et al. 2012; Koori et al. 2014). In particular, periodontal ligament cells were recently shown to have the capacity to undergo osteogenic differentiation upon $\mathrm{Ca}^{2+}$ treatment in an L-VGCC-dependent manner as demonstrated by suppressed osteogenic differentiation using nifedipine, a known L-VGCC inhibitor (Koori et al. 2014). In contrast, Barradas et al. (2012) did not see a notable difference when treating with nifedipine. Recently, Ju et al. (2015) reported that $\mathrm{Ca} 1.2$ of the L-VGCC plays an essential role in the odontogenic and neural differentiation of DPSCs, which might be mediated through the regulation of distal C-terminus levels in DPSCs. Further studies should be performed to define a predominant role of the L-VGCC or ORAI1 in the odontogenic differentiation and mineralization of DPSCs.

In summary, we have demonstrated the important role of ORAI1 in the odontogenic differentiation and mineralization of DPSCs both in vitro and in vivo. Our study suggests that 


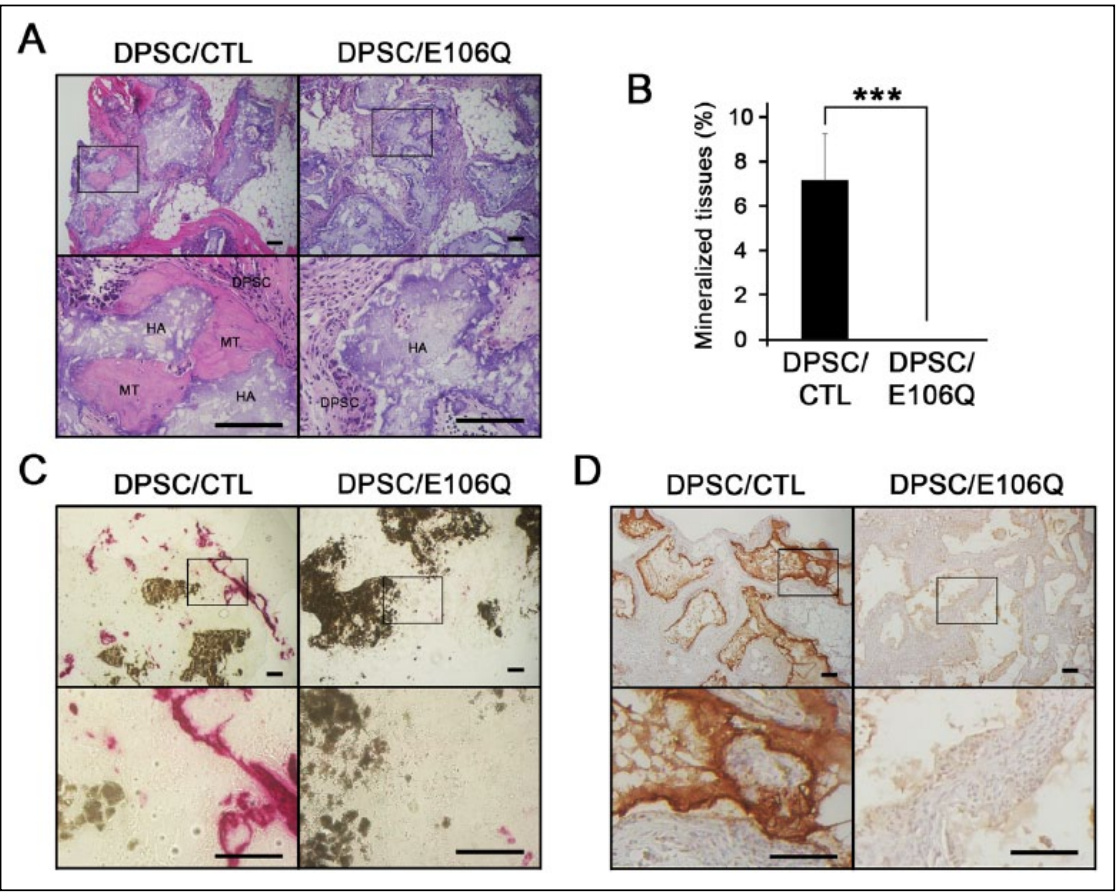

Figure 4. The dominant negative mutant ORAII ${ }^{E 106 Q}$ inhibits the odontogenic differentiation and mineralization of dental pulp stem cells (DPSCs) in vivo. (A) DPSC/CTL and DPSC/EI06Q cells were transplanted subcutaneously into the dorsal suprascapular regions of 10 -wk-old immunocompromised nude mice. The nodules were harvested after $8 \mathrm{wk}$, and the formalinfixed paraffin-embedded (FFPE) section was prepared for hematoxylin and eosin staining. HA, hydroxyapatite scaffolds; MT, mineralized tissue. (B) The mineralized tissues were quantified $(n=$ 4). (C) The cryosection was subjected to alkaline phosphatase staining. (D) The FFPE section was subjected to immunohistochemistry using DMPI antibody. The bar represents $100 \mu \mathrm{m}$.

\section{References}

Apati A, Paszty K, Erdei Z, Szebenyi K, Homolya L, Sarkadi B. 2012. Calcium signaling in pluripotent stem cells. Mol Cell Endocrinol. 353(1-2):57-67.

Bakland LK, Andreasen JO. 2012. Will mineral trioxide aggregate replace calcium hydroxide in treating pulpal and periodontal healing complications subsequent to dental trauma? A review. Dent Traumatol. 28(1):25-32.

Barradas AM, Fernandes HA, Groen N, Chai YC, Schrooten J, van de Peppel J, van Leeuwen JP, van Blitterswijk CA, de Boer J. 2012. A calcium-induced signaling cascade leading to osteogenic differentiation of human bone marrow-derived mesenchymal stromal cells. Biomaterials. 33(11):3205-3215.

Barradas AM, Monticone V, Hulsman M, Danoux C, Fernandes H, Tahmasebi Birgani Z, Barrere-de Groot F, Yuan H, Reinders M, Habibovic P, et al. 2013. Molecular mechanisms of biomaterialdriven osteogenic differentiation in human mesenchymal stromal cells. Integr Biol (Camb). 5(7):920-931.

Camilleri J. 2014. Hydration characteristics of Biodentine and Theracal used as pulp capping materials. Dent Mater. 30(7):709-715.

Cheng S, Wang W, Lin Z, Zhou P, Zhang X, Zhang W, Chen Q, Kou D, Ying X, Shen Y, et al. 2013. Effects of extracellular calcium on viability and osteogenic differentiation of bone marrow stromal cells in vitro. Hum Cell. 26(3):114-120.

Fan Z, Yamaza T, Lee JS, Yu J, Wang S, Fan G, Shi S, Wang CY. 2009. BCOR regulates mesenchymal stem cell function by epigenetic mechanisms. Nat Cell Biol. 11(8):1002-1009.

Ferracane JL, Cooper PR, Smith AJ. 2010. Can interaction of materials with the dentin-pulp complex contribute to dentin regeneration? Odontology. 98(1):2-14.

ORAI1 may provide a therapeutic target to expedite pulpal wound healing in regenerating reparative dentin.

\section{Author Contributions}

S. Sohn, R.H. Kim, contributed to conception, design, data acquisition, analysis, and interpretation, drafted and critically revised the manuscript; Y. Park, contributed to design, data acquisition, and analysis, critically revised the manuscript; S. Srikanth, contributed to data acquisition and analysis, critically revised the manuscript; A. Arai, M. Song, B. Yu, contributed to data acquisition, critically revised the manuscript; K.-H. Shin, contributed to conception and data analysis, critically revised the manuscript; M.K. Kang, C. Wang, Y. Gwack, N.-H. Park, contributed to conception and data interpretation, critically revised the manuscript. All authors gave final approval and agree to be accountable for all aspects of the work.

\section{Acknowledgments}

This study was supported by grants from the National Institutes of Health/National Institute of Dental and Craniofacial Research (DE021114 and DE023348 to R.H.K.) and a Dean's Faculty Research Seed grant (R.H.K.). The authors declare no potential conflicts of interest with respect to the authorship and/or publication of this article.
Feske S, Gwack Y, Prakriya M, Srikanth S, Puppel SH, Tanasa B, Hogan PG, Lewis RS, Daly M, Rao A. 2006. A mutation in Orail causes immune deficiency by abrogating CRAC channel function. Nature. 441(7090):179-185.

Gronthos S, Brahim J, Li W, Fisher LW, Cherman N, Boyde A, DenBesten P, Robey PG, Shi S. 2002. Stem cell properties of human dental pulp stem cells. J Dent Res. 81(8):531-535.

Gronthos S, Mankani M, Brahim J, Robey PG, Shi S. 2000. Postnatal human dental pulp stem cells (DPSCs) in vitro and in vivo. Proc Natl Acad Sci U S A. 97(25):13625-13630.

Gwack Y, Srikanth S, Feske S, Cruz-Guilloty F, Oh-hora M, Neems DS, Hogan PG, Rao A. 2007. Biochemical and functional characterization of Orai proteins. J Biol Chem. 282(22):16232-16243.

Hilton TJ, Ferracane JL, Mancl L, Northwest Practice-based Research Collaborative in Evidence-based Dentistry. 2013. Comparison of $\mathrm{CaOH}$ with MTA for direct pulp capping: a PBRN randomized clinical trial. J Dent Res. 92(7 Suppl):16S-22S.

Hwang SY, Foley J, Numaga-Tomita T, Petranka JG, Bird GS, Putney JW Jr. 2012. Deletion of Orail alters expression of multiple genes during osteoclast and osteoblast maturation. Cell Calcium. 52(6):488-500.

Jørgensen NR, Henriksen Z, Brot C, Eriksen EF, Sørensen OH, Civitelli R, Steinberg TH. 2000. Human osteoblastic cells propagate intercellular calcium signals by two different mechanisms. J Bone Miner Res. 15(6):1024-1032.

Ju Y, Ge J, Ren X, Zhu X, Xue Z, Feng Y, Zhao S. 2015. Ca1.2 of L-type calcium channel is a key factor for the differentiation of dental pulp stem cells. J Endod. 41(7):1048-1055.

Kim KD, Srikanth S, Yee MK, Mock DC, Lawson GW, Gwack Y. 2011 ORAI1 deficiency impairs activated $\mathrm{T}$ cell death and enhances $\mathrm{T}$ cell survival. J Immunol. 187(7):3620-3630.

Kim RH, Lieberman MB, Lee R, Shin KH, Mehrazarin S, Oh JE, Park NH, Kang MK. 2010. Bmi-1 extends the life span of normal human oral keratinocytes by inhibiting the TGF-beta signaling. Exp Cell Res. 316(16):2600-2608.

Kim RH, Williams DW, Bae S, Lee RS, Oh JE, Mehrazarin S, Kim T, Shin KH, Park NH, Kang MK. 2013. Camphorquinone inhibits odontogenic 
differentiation of dental pulp cells and triggers release of inflammatory cytokines. J Endod. 39(1):57-61.

Kohn DH, Sarmadi M, Helman JI, Krebsbach PH. 2002. Effects of pH on human bone marrow stromal cells in vitro: implications for tissue engineering of bone. J Biomed Mater Res. 60(2):292-299.

Koori K, Maeda H, Fujii S, Tomokiyo A, Kawachi G, Hasegawa D, Hamano S, Sugii H, Wada N, Akamine A. 2014. The roles of calcium-sensing receptor and calcium channel in osteogenic differentiation of undifferentiated periodontal ligament cells. Cell Tissue Res. 357(3):707-718.

Lin LM, Rosenberg PA. 2011. Repair and regeneration in endodontics. Int Endod J. 44(10):889-906.

Luca L, Rougemont AL, Walpoth BH, Gurny R, Jordan O. 2010. The effects of carrier nature and $\mathrm{pH}$ on rhBMP-2-induced ectopic bone formation. J Control Release. 147(1):38-44.

McCarl CA, Picard C, Khalil S, Kawasaki T, Rother J, Papolos A, Kutok J, Hivroz C, Ledeist F, Plogmann K, et al. 2009. ORAI1 deficiency and lack of store-operated $\mathrm{Ca} 2+$ entry cause immunodeficiency, myopathy, and ectodermal dysplasia. J Allergy Clin Immunol. 124(6):1311-1318.e7.

Mehrazarin S, Oh JE, Chung CL, Chen W, Kim RH, Shi S, Park NH, Kang MK. 2011. Impaired odontogenic differentiation of senescent dental mesenchymal stem cells is associated with loss of Bmi-1 expression. J Endod. 37(5):662-666.

Nakamura S, Matsumoto T, Sasaki J, Egusa H, Lee KY, Nakano T, Sohmura T, Nakahira A. 2010. Effect of calcium ion concentrations on osteogenic differentiation and hematopoietic stem cell niche-related protein expression in osteoblasts. Tissue Eng Part A. 16(8):2467-2473.

Natale LC, Rodrigues MC, Xavier TA, Simoes A, de Souza DN, Braga RR. 2015. Ion release and mechanical properties of calcium silicate and calcium hydroxide materials used for pulp capping. Int Endod J. 48(1):89-94.

Nowicka A, Lipski M, Parafiniuk M, Sporniak-Tutak K, Lichota D, Kosierkiewicz A, Kaczmarek W, Buczkowska-Radlinska J. 2013. Response of human dental pulp capped with Biodentine and mineral trioxide aggregate. J Endod. 39(6):743-747.

Parekh AB, Putney JW Jr. 2005. Store-operated calcium channels. Physiol Rev. 85(2):757-810.
Picard C, McCarl CA, Papolos A, Khalil S, Luthy K, Hivroz C, LeDeist F, Rieux-Laucat F, Rechavi G, Rao A, et al. 2009. STIM1 mutation associated with a syndrome of immunodeficiency and autoimmunity. N Engl J Med. 360(19):1971-1980.

Prakriya M, Feske S, Gwack Y, Srikanth S, Rao A, Hogan PG. 2006. Orai1 is an essential pore subunit of the CRAC channel. Nature. 443(7108):230-233.

Rashid F, Shiba H, Mizuno N, Mouri Y, Fujita T, Shinohara H, Ogawa T, Kawaguchi $\mathrm{H}, \mathrm{Kurihara} \mathrm{H} .2003$. The effect of extracellular calcium ion on gene expression of bone-related proteins in human pulp cells. J Endod. 29(2):104-107.

Robinson LJ, Mancarella S, Songsawad D, Tourkova IL, Barnett JB, Gill DL, Soboloff J, Blair HC. 2012. Gene disruption of the calcium channel Orail results in inhibition of osteoclast and osteoblast differentiation and impairs skeletal development. Lab Invest. 92(7):1071-1083.

Sangwan P, Sangwan A, Duhan J, Rohilla A. 2013. Tertiary dentinogenesis with calcium hydroxide: a review of proposed mechanisms. Int Endod J. 46(1):3-19.

Simon SR, Berdal A, Cooper PR, Lumley PJ, Tomson PL, Smith AJ. 2011. Dentin-pulp complex regeneration: from lab to clinic. Adv Dent Res. 23(3):340-345.

Srikanth S, Gwack Y. 2013. Orail-NFAT signalling pathway triggered by T cell receptor stimulation. Mol Cells. 35(3):182-194.

Tada H, Nemoto E, Kanaya S, Hamaji N, Sato H, Shimauchi H. 2010. Elevated extracellular calcium increases expression of bone morphogenetic protein-2 gene via a calcium channel and ERK pathway in human dental pulp cells. Biochem Biophys Res Commun. 394(4):1093-1097.

Tonelli FM, Santos AK, Gomes DA, da Silva SL, Gomes KN, Ladeira LO, Resende RR. 2012. Stem cells and calcium signaling. Adv Exp Med Biol. 740:891-916.

Williams DW, Wu H, Oh JE, Fakhar C, Kang MK, Shin KH, Park NH, Kim RH. 2013. 2-Hydroxyethyl methacrylate inhibits migration of dental pulp stem cells. J Endod. 39(9):1156-1160.

Yuan H, Fernandes H, Habibovic P, de Boer J, Barradas AM, de Ruiter A, Walsh WR, van Blitterswijk CA, de Bruijn JD. 2010. Osteoinductive ceramics as a synthetic alternative to autologous bone grafting. Proc Natl Acad Sci U S A. 107(31):13614-13619. 